\title{
PBDEs in marine and freshwater sediments from Belgium: levels, profiles and relations with biota
}

\author{
Stefan Voorspoels, * Adrian Covaci, Johan Maervoet and Paul Schepens
}

Toxicological Center, University of Antwerp (U.A.), Universiteitsplein 1, 2610 Wilrijk, Belgium. E-mail: stefan.voorspoels@ua.ac.be; Fax: +32 3820 2722; Tel: +32 38202704

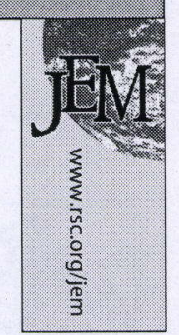

Received 6th July 2004, Accepted 6th September 2004

First published as an Advance Article on the web 22nd October 2004

Sediments from the Belgian North Sea (BNS), the Western Scheldt Estuary (SE) and freshwater watercourses from the Scheldt basin were analysed for eight PBDE congeners, namely BDEs 28, 47, 99, 100, 153, 154, 183 and 209. Previously analysed biological samples from the same locations in the BNS and the SE have been shown to contain large amounts of PBDEs. Surprisingly, PBDE concentrations in the sediments were below the LOQ for samples from the BNS (except BDE 209), while in those from the SE the sum of PBDEs (not including BDE 209) were higher and ranged from 0.20 to $0.41 \mathrm{ng} \mathrm{g}^{-1} \mathrm{dw}$. BDE 209 could be detected in $83 \%$ of the samples from the BNS and in all the samples from the SE. Concentrations up to $1200 \mathrm{ng} \mathrm{g}^{-1}$ were hereby measured in the SE. Compared to the marine and estuarine locations, the sediments from the freshwater watercourses were relatively more polluted with the lower brominated PBDEs $\left(<0.20-19 \mathrm{ng} \mathrm{g}^{-1}\right.$ dw). BDE 209 concentrations up to $320 \mathrm{ng} \mathrm{g}^{-1} \mathrm{dw}$ were measured in those sediments. However, the contribution of BDE 209 to the total amount of PBDEs varied much more at the freshwater locations than in the SE, which suggests a different input of pollutants. PBDE profiles observed in biological samples do not match the profiles of the sediments. BDE 183 and 209 could not be quantified in biota, although these congeners were undoubtedly present in the sediments. This raises questions about the bioavailability of these congeners in the environment.

\section{Introduction}

Polybrominated diphenyl ethers (PBDEs) are used as flame retardants to improve the fire safety of various items. These chemicals have shown a rise in production since they were first introduced in the 1960 s, with a substantial increase since the end of the 1970 s due to the growing popularity of computers and other electronic equipment. ${ }^{1}$ Of the total worldwide market demand for PBDEs in 2001, more than $80 \%$ consisted of the fully brominated decabromodiphenyl ether (BDE 209). ${ }^{2}$ This PBDE congener is of special interest because its presence is being increasingly reported worldwide. However, a ban on use or production is not foreseen, because environment and human risk assessment reports have concluded that there is no significant risk. ${ }^{3}$

Both biotic and abiotic compartments are polluted with PBDEs. ${ }^{1,4}$ This is why brominated flame retardants (BFRs), and especially PBDEs, have received increasing attention during recent years. ${ }^{4-6}$ Their extremely resistant and lipophilic nature is partly responsible for their widespread presence. ${ }^{4}$ These properties cause residues of these persistent organic pollutants (POPs) to bioaccumulate in the organic fraction of soils and sediments, and in adipose tissues of biota, which results in an enrichment throughout the food chain. $^{7}$

The water solubility and vapour pressure of PBDEs are very low causing them to be adsorbed rapidly onto solid particles of sediment and soil when released into the environment. ${ }^{8,9}$ Sediment and sewage sludge are therefore considered a sink for these pollutants, although pollutants can be still bioavailable once adsorbed to the sediment particles. ${ }^{10,11}$

m Soil and sediment studies can provide valuable information about the pollution load in a certain area. Additionally, the study of sediments is an important step in mapping possible exposure pathways to various marine and freshwater organisms.

The area studied in this article covers the Belgian North Sea (BNS) and the Western Scheldt Estuary (SE). The drainage basin of the SE covers a very densely populated and highly industrialised region, resulting in a high pollution level with POPs $^{12-14}$ as well as heavy metals ${ }^{15}$ and non-persistent pollutants. ${ }^{16}$ The present study focused on the determination of PBDEs in sediments sampled at predefined locations in both the BNS and the SE. Previous studies have revealed a correlation between distance to Antwerp and degree of pollution in benthic invertebrates and fish. ${ }^{12,13}$ Additionally, 14 sediment samples were taken from tributaries of the Scheldt to assess sediment pollution at several inland locations in the Scheldt basin.

\section{Materials and methods}

\section{Sampling}

Six locations in the BNS (S1-S6), 11 locations in the SE (S7$\mathrm{S} 17)$, and 14 freshwater locations in rivers and watercourses of the Scheldt Bassin (T1-T14) were sampled (Fig. 1). Surface sediments from the BNS and SE were taken in October and November 2001 using a Van Veen surface sediment sampler during a cruise with the research vessel Zeeleeuw, provided by the Flemish Marine Institute (VLIZ). Because the Scheldt is the main gateway to the Antwerp harbour, the river is highly trafficked and dredged. In order to avoid sampling at sites that were subjected to dredging, a map that showed the dredging activities was used to determine the appropriate sampling locations.

At each location, 4 subsamples of approximately $10 \mathrm{~L}$ sediment were taken within a radius of $50 \mathrm{~m}$ and combined. The approximate sampling depth was $20-25 \mathrm{~cm}$. The sediment was kept in hexane pre-washed glass receptacles at $+4{ }^{\circ} \mathrm{C}$ until further processing.

The samples from rivers and watercourses of the Scheldt basin were collected with a 'Petit Ponar' grab sampler during August and September 2001. At each site a mixed sample composed of 5 grab samples was taken. The sediments were sieved with $5 \mathrm{~L}$ of the site-water using a $200 \mu \mathrm{m}$-mesh sieve to 


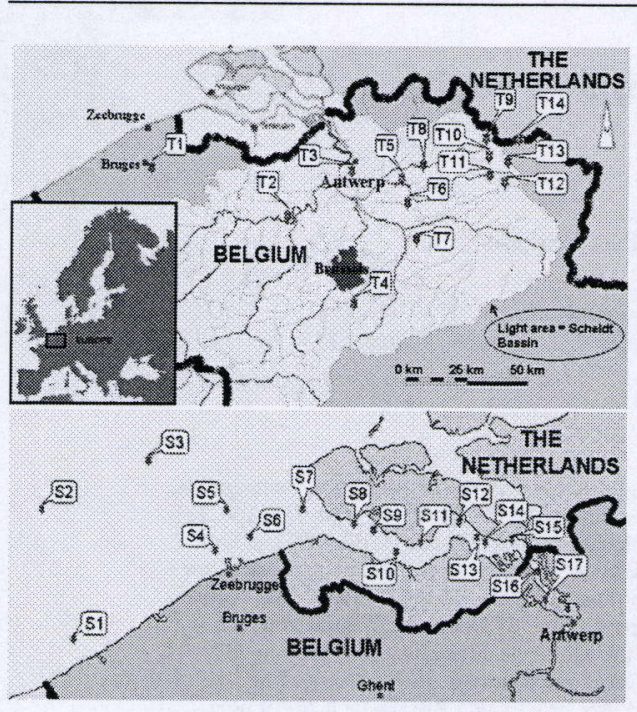

Fig. 1 Sampling locations.

remove the organisms. The sediment was stored in $500 \mathrm{~m}$ polyethylene beakers at $+4{ }^{\circ} \mathrm{C}$ until further processing.

\section{Targeted compounds}

Based on reported abundance ${ }^{12-17}$ and toxicity, ${ }^{4}$ the following BDE-congeners (IUPAC numbering) were targeted for analysis: $28,47,99,100,153,154,183$, and 209. Brominated biphenyl (BB) 103 was used as IS for BDE 28 and 47, and BB 155 was used as IS for BDE 99, 100, 153, 154, and 183. ${ }^{13}$ C-labeled BDE 209 was used as IS for BDE 209.

\section{Chemicals}

All solvents used for the analysis ( $n$-hexane, acetone, dichloromethane, and iso-octane) were of SupraSolv $($ grade (Merck, Darmstadt, Germany). Cu powder was >200 Mesh (Merck, Darmstadt, Germany). Individual reference standards for each compound were used for identification and quantification (CIL, Andover, USA; Dr Ehrenstorfer Laboratories, Augsburg, Germany).

\section{Extraction and clean up}

The sediments from BNS and SE were dried for 1 week at room temperature until constant weight and consecutively sieved through $1 \mathrm{~mm}$ and $180 \mu \mathrm{m}$ hexane-washed stainless steel sieves. The fine fraction was homogenised and used for analysis. The sediments from the freshwater locations were freeze-dried, sieved through a $180 \mu \mathrm{m}$ hexane pre-washed stainless steel sieve and the fine fraction was further homogenised.

Between 1 and $5 \mathrm{~g}$ of dried homogenised sediment was mixed with $\mathrm{Cu}$ powder (triple amount of sample intake) and transferred into a hexane-rinsed extraction thimble and spiked with IS. The samples were extracted for $2.5 \mathrm{~h}$ with hexaneacetone $(3: 1 ; v / v)$ by means of an accelerated Soxhlet extractor B-811 (Büchi, Switzerland). The extract was cleaned-up using a multi-layer silica cartridge, containing $\mathrm{Cu}$ powder, silica impregnated with concentrated sulfuric acid (44\%) and silica impregnated with $\mathrm{KOH}(33 \%)$. PBDEs were eluted with $n$-hexane followed by dichloromethane. The eluate was concentrated to near dryness and the extract was re-solubilised in $80 \mu \mathrm{l}$ iso-octane.

\section{Gas chromatography-mass spectrometry}

Details of the instrumental set-up were previously described by Voorspoels et al. ${ }^{12}$ In short, all PBDE analyses were performed using an Agilent $6890 \mathrm{GC}$ (Palo Alto, USA) connected to an Agilent 5973 mass spectrometer. PBDE congeners $28,47,99,100$, 153,154 , and 183 were analysed on a $25 \mathrm{~m} \times 0.22 \mathrm{~mm} \times 0.25 \mu \mathrm{m}$ HT-8 capillary column (SGE, Zulte, Belgium). For these congeners the mass spectrometer was operated in electron capture negative ionisation (ECNI) in the selected ion-monitoring (SIM) mode at the $m / z=79$ and 81 . For the analysis of BDE 209, a $12 \mathrm{~m} \times 0.18 \mathrm{~mm} \times 0.10 \mu \mathrm{m}$ AT-5 capillary column (Alltech, Lokeren, Belgium) was used. The mass spectrometer was operated in ECNI in SIM mode at the $m / z$ ratios of $484.7 / 486.7$ and 494.7/496.7 for BDE 209 and ${ }^{13}$ C-BDE 209, respectively.

\section{Quality assurance}

The quality control (QC) was done by regular injection of solvent blanks and standard solutions. Each batch of 8 samples included a procedural blank, blind duplicate sample and inhouse reference material (the sediment sample used for the BROC interlaboratory feasibility study). ${ }^{18}$ The individual PBDE-congener concentrations did not differ more than $15 \%$ from the mean values obtained in the BROC-study. Recoveries of all congeners varied between 83 and $92 \%$ (RSD $<16 \%$ ).

Procedural blanks for all PBDEs were consistent (RSD around $30 \%$ ) and therefore the median blank values for these compounds were used for subtraction. Blanks for BDE 209 were one order of magnitude higher than for the other PBDEcongeners. The limit of quantification (LOQ) was determined by laboratory background levels. Two times the standard deviation of the procedural blank level was used as the LOQ, resulting in a certainty of more than $95 \%$ of the presented results.

\section{Statistical analysis}

Only samples that had measurable amounts (>LOQ) of analytes were used for the statistical calculations. Simple linear regression was used to test for correlations between the total PBDE load and BDE 209 levels. To test for differences between profiles, an ANOVA with Scheffe's post hoc test was performed. Tests were considered significant if $p$ was lower than 0.05 . All statistical tests were performed using Statistica $(\mathbb{B})$ v5.0 software (StatSoft Inc., Tulsa, USA).

\section{Results and discussion \\ PBDE levels}

All results are summarised in Table 1. Levels of PBDEs in the BNS samples were low and the majority of congeners were below the LOQ. The sum of PBDEs (BDE 28, 47, 99, 100, 153, 154 and 183; hereafter referred to as "sum of PBDEs") was never higher than the calculated LOQ for these locations $(<0.2$ $n \mathrm{ng}^{-1} \mathrm{dw}$ ). BDE 209, however, could be detected in $83 \%$ of samples from the BNS, although at rather low concentrations (1.1-24 $\left.\mathrm{ng} \mathrm{g}^{-1} \mathrm{dw}\right)$. Locations near the industrial harbour of Zeebrugge (S4; S6) were the only locations in the BNS where tri- to hexa-PBDEs could be measured and where BDE 209 showed a tenfold higher concentration compared to the other locations in the BNS (Table 1). Near the harbour of Vlissingen, (locations S7 and S8), slightly but statistically significant elevated BDE 209 levels were seen. However, in sediments taken further upstream in the SE, levels were low and comparable to the concentrations in the BNS until location S15 (near the Dutch-Belgian border).

At locations S7 to S14 (SE) the sum of PBDEs ranged from $<0.20$ to $0.41 \mathrm{ng} \mathrm{g}^{-1} \mathrm{dw}$. Similar to the other PBDEs, concentrations of BDE 209 were relatively low at these 
Table 1 Concentrations ( $\mathrm{ng} \mathrm{g}^{-1} \mathrm{dw}$ ) for individual BDE congeners in sediments from the BNS, SE and freshwater watercourses

\begin{tabular}{|c|c|c|c|c|c|c|c|c|c|c|}
\hline & Location & BDE 28 & BDE 47 & BDE 100 & BDE 99 & BDE 154 & BDE 153 & BDE 183 & Sum PBDEs ${ }^{a}$ & BDE 209 \\
\hline \multirow[t]{6}{*}{ BNS } & S1 & $<0.01$ & $<0.07$ & $<0.02$ & $<0.1$ & $<0.01$ & $<0.01$ & $<0.01$ & $<0.2$ & 1.1 \\
\hline & S2 & $<0.01$ & $<0.07$ & $<0.02$ & $<0.1$ & $<0.01$ & $<0.01$ & $<0.01$ & $<0.2$ & 1.2 \\
\hline & S3 & $<0.01$ & $<0.07$ & $<0.02$ & $<0.1$ & $<0.01$ & $<0.01$ & $<0.01$ & $<0.2$ & 1.1 \\
\hline & S4 & $<0.01$ & $<0.07$ & $<0.02$ & $<0.1$ & 0.03 & 0.01 & $<0.01$ & $<0.2$ & 24 \\
\hline & S5 & $<0.01$ & $<0.07$ & $<0.02$ & $<0.1$ & $<0.01$ & $<0.01$ & $<0.01$ & $<0.2$ & 2.9 \\
\hline & S6 & $<0.01$ & 0.08 & 0.02 & $<0.1$ & 0.03 & $<0.01$ & $<0.01$ & $<0.2$ & 23 \\
\hline \multirow[t]{11}{*}{ SE } & S7 & 0.01 & $<0.07$ & $<0.02$ & $<0.1$ & 0.02 & $<0.01$ & $<0.01$ & $<0.2$ & 17 \\
\hline & S8 & 0.06 & 0.24 & 0.04 & $<0.1$ & 0.04 & 0.03 & $<0.01$ & $<0.2$ & 47 \\
\hline & S9 & $<0.01$ & $<0.07$ & $<0.02$ & $<0.1$ & 0.01 & $<0.01$ & $<0.01$ & $<0.2$ & 1.5 \\
\hline & S10 & 0.02 & 0.10 & 0.03 & $<0.1$ & 0.02 & 0.02 & $<0.01$ & 0.41 & 5.7 \\
\hline & S11 & $<0.01$ & $<0.07$ & $<0.02$ & $<0.1$ & 0.01 & $<0.01$ & $<0.01$ & $<0.2$ & 6.1 \\
\hline & $\mathrm{S} 12$ & $<0.01$ & 0.09 & 0.03 & 0.10 & 0.02 & 0.02 & $<0.01$ & 0.26 & 2.8 \\
\hline & $\mathrm{S} 13$ & 0.01 & 0.07 & 0.03 & 0.10 & 0.02 & 0.02 & $<0.01$ & 0.26 & 1.9 \\
\hline & $\mathrm{S} 14$ & 0.01 & 0.09 & 0.03 & 0.10 & 0.02 & 0.02 & $<0.01$ & 0.27 & n.a. \\
\hline & S15 & 1.1 & 6.1 & 1.9 & 6.1 & 1.2 & 1.0 & 0.15 & 18 & 1200 \\
\hline & S16 & 0.46 & 3.7 & 1.00 & 3.6 & 0.79 & 0.72 & 0.33 & 11 & 550 \\
\hline & S17 & 0.19 & 1.9 & 0.53 & 2.0 & 0.29 & 0.28 & 0.06 & 5.3 & 340 \\
\hline \multirow[t]{14}{*}{ TRIBUTARIES } & $\mathrm{Tl}$ & 0.01 & 3.9 & 0.04 & 0.16 & 0.03 & 0.03 & 0.03 & 4.2 & 320 \\
\hline & $\mathrm{T} 2$ & 0.05 & 0.38 & 0.09 & 0.40 & 0.06 & 0.07 & 0.10 & 1.2 & 8.1 \\
\hline & $\mathrm{T} 3$ & 0.02 & 0.09 & 0.04 & 0.12 & 0.03 & 0.04 & 0.06 & 0.38 & 6.0 \\
\hline & $\mathrm{T} 4$ & 0.01 & $<0.07$ & $<0.02$ & $<0.1$ & 0.03 & 0.02 & 0.04 & $<0.2$ & 1.6 \\
\hline & T5 & 0.02 & 0.29 & 0.07 & 0.37 & 0.06 & 0.07 & 0.08 & 0.96 & 10 \\
\hline & T6 & 0.22 & 5.6 & 1.15 & 7.4 & 3.0 & 1.0 & 0.78 & 19 & 24 \\
\hline & $\mathrm{T} 7$ & 0.02 & 0.19 & 0.04 & 0.25 & 0.04 & 0.04 & 0.04 & 0.63 & 2.4 \\
\hline & $\mathrm{T} 8$ & 0.02 & $<0.07$ & 0.02 & $<0.1$ & 0.02 & 0.02 & $<0.01$ & $<0.2$ & $<0.1$ \\
\hline & $\mathrm{T} 9$ & 0.01 & 0.11 & 0.03 & 0.13 & 0.13 & 0.02 & 0.02 & 0.44 & 0.5 \\
\hline & $\mathrm{T} 10$ & 0.01 & $<0.07$ & 0.02 & $<0.1$ & 0.08 & 0.02 & $<0.01$ & $<0.2$ & $<0.1$ \\
\hline & $\mathrm{T} 11$ & 0.01 & $<0.07$ & $<0.02$ & $<0.1$ & 0.02 & 0.01 & $<0.01$ & $<0.2$ & 0.5 \\
\hline & $\mathrm{T} 12$ & 0.03 & 0.09 & 0.04 & 0.14 & 0.16 & 0.04 & 0.07 & 0.57 & 8.2 \\
\hline & $\mathrm{T} 13$ & 0.01 & $<0.07$ & $<0.02$ & $<0.1$ & 0.03 & 0.01 & $<0.01$ & $<0.2$ & 0.5 \\
\hline & $\mathrm{T} 14$ & 0.01 & $<0.07$ & $<0.02$ & $<0.1$ & 0.02 & 0.02 & 0.05 & $<0.2$ & 120 \\
\hline
\end{tabular}

${ }^{a}$ BDE 209 is not included in the sum of PBDEs; n.a. = not available.

locations in the SE $\left(1.5-47 \mathrm{ng} \mathrm{g}^{-1} \mathrm{dw}\right)$. At locations $\mathrm{S} 15$ to $\mathrm{S17}$, concentrations of the lower brominated PBDEs were approximately 10 to 50 times higher than at downstream locations $\left(5.3-18 \mathrm{ng} \mathrm{g}^{-1} \mathrm{dw}\right)$. At the same locations, very high levels of BDE 209 could also be measured (up to $1200 \mathrm{ng} \mathrm{g}^{-1} \mathrm{dw}$ ).

The Scheldt discharges into the North Sea, projecting its plume even further than Zeebrugge. ${ }^{19}$ Because BDE 209 concentrations in the SE are relatively low until location S15, it is highly unlikely that the elevated levels found near the Zeebrugge harbour are caused by the influence of the SE. The higher levels found near Zeebrugge (S4; S6) and near the Dutch-Belgian border (S15-S17) were probably caused by the industrial harbours of Zeebrugge and Antwerp, respectively. However, the latter is doubtful because location S15 displayed the highest levels and concentrations decrease further upstream. Local input near location S15 may therefore be involved. Higher contamination close to populated areas like harbours and urban centres has been previously reported by others. $^{20,21}$

Compared to the marine and estuarine locations, freshwater sediments seem to be more polluted with PBDEs $(<0.20-19 \mathrm{ng}$ $\mathrm{g}^{-1} \mathrm{dw}$ ). The sum of PBDEs at location T6 was the highest one found in this study $\left(19 \mathrm{ng} \mathrm{g}^{-1} \mathrm{dw}\right)$. However, BDE 209 was present at rather low concentration at this location $\left(24 \mathrm{ng} \mathrm{g}^{-1}\right.$ dw). A point-source for the lower brominated congeners can therefore not be ruled out at this location.

BDE 209 could be detected in $86 \%$ of the freshwater samples, with concentrations up to $320 \mathrm{ng} \mathrm{g}^{-1} \mathrm{dw}$ (at location T1). These elevated concentrations are probably related to the heavy industrialisation and dense population of this region and thus caused by the higher impact of human activity on the inland watercourses. Christensen and Platz have also reported higher PBDE contamination in freshwater than in marine sediments. $^{20}$

De Boer et al. reported comparable levels for sediments from The Netherlands ${ }^{22}$ In that study, concentrations up to $7.1 \mathrm{ng}$ $\mathrm{g}^{-1} \mathrm{dw}, 5.5 \mathrm{ng} \mathrm{g}^{-1} \mathrm{dw}$ and $510 \mathrm{ng} \mathrm{g}^{-1} \mathrm{dw}$ for BDEs 47, 99 and 209 were reported, respectively. The samples were taken with a Van Veen surface sediment sampler similar to the one used in the present study.

Levels of BDE 47 in sediments from the UK that were taken at or around potential PBDE sources were up to 2 orders of magnitude higher $\left(368 \mathrm{ng} \mathrm{g}^{-1} \mathrm{dw}\right.$ ) than in the present study. ${ }^{17}$ In general, PBDE-concentrations in that study were slightly higher than the sediments from the freshwater locations in the present study. The sediment samples were taken with a small hand-held Van Veen surface sediment sampler, which enabled only taking the first centimetres of the sediment. This is in contrast with the larger Van Veen sampler used in the present study, which sampled up to 25 centimetres depth.

Christensen and Platz collected top-layer $(0-2 \mathrm{~cm})$ marine sediments in Denmark. ${ }^{20}$ Concentrations of the sum of PBDEs ranged from 0.06 to $3.7 \mathrm{ng} \mathrm{g}^{-1} \mathrm{dw}$; BDE 209 levels up to $22 \mathrm{ng}$ $\mathrm{g}^{-1} \mathrm{dw}$ were reported. The sediments that originated from the area of the Copenhagen harbour were the most polluted. These sum of PBDEs concentrations were in the same order of magnitude as the sediments in parts of the SE in the present study. BDE 209 concentrations in the SE in the present study were up to 60 times higher $\left(1200 \mathrm{ng} \mathrm{g}^{-1}\right)$ than those reported from Denmark. Compared to values reported in literature, ${ }^{20-23}$ it can be concluded that levels of BDE 209 in the SE (S15-S17) are relatively high. 


\section{PBDE profiles}

BDE 209 was the most abundant congener, followed by BDE 47 and 99 . These profile characteristics have been previously reported by Zegers et al. for Western Europe. ${ }^{24}$ In the present study, profiles were calculated based only on BDE 28 to 183 As BDE 209 was not included in the profile, it was possible to compare the results with the Bromkal DE70-5 technical pentamixture and other studies. Including this congener in the profile would also bias the ratios, because the contribution of BDE 209 to the total PBDE-load was $95 \pm 4.7 \%$ for the SE samples and varied between $52 \%$ (T9) and $99 \%$ (T1) for the tributaries.

For BNS samples no profile could be established due to the very low PBDE-levels. The profile calculated for the SE was very consistent (RSD $<20 \%$, except for BDE 183) (Fig. 2) The profile calculated for the tributaries was less consisten (RSD up to $70 \%$ ), which can be explained by their geographical distribution; samples T9 and T12 displayed relatively high levels of BDE 154, which influenced the pattern to a rather great extent. The profile at location $\mathrm{T} 1$ also deviated, because the levels of BDE 47 were relatively high. Sample T1 was therefore not included in the mean profile calculation.

No significant profile differences were found between the SE and the tributaries. Both sample sets display a similar profile to the Bromkal 70-5DE pentaBDE technical mixture (Fig. 2).

\section{Relations with biota}

Although the sum of PBDEs was below the LOQ in the BNS sediments, a similar study performed on mildly migrating benthic invertebrates (such as crab, starfish, shrimp) and fish species (such as dab, plaice, sole, bib, and whiting) reported values for the samples from BNS between $0.02 \mathrm{ng} \mathrm{g}^{-1}$ ww and $108 \mathrm{ng} \mathrm{g}^{-1}$ ww. $^{12}$ In the same study, concentrations in biota from the SE ranged from 0.20 to $980 \mathrm{ng} \mathrm{g}^{-1}$ ww. $^{12}$

A significant inverse correlation $\left(r^{2}\right.$ up to $\left.0.77 ; p=0.02\right)$ between PBDE-concentrations in biota from the SE and the distance to Antwerp was also observed in that study. ${ }^{12}$ This correlation was not reflected in the data of the sediments, although sediment is the most likely source of contaminants for the biota living above it, since contaminants trapped on the sediments may be bioavailable to sediment dwelling organisms. ${ }^{10,11}$

The sampling locations in the present study were away from any known dredging activity. The low levels found in the sediments could certainly not have been caused by sampling flaw (location). The lack of any correlation between levels and location and the discrepancy between levels in biota and sediments can probably be explained by the sampling methodology. As mentioned previously, sediments of the presen study were sampled using a large Van Veen surface sediment sampler. This device however did not only sample the top layer $(\sim 1 \mathrm{~cm})$, but went much deeper into the sediment $(\sim 20-25$ $\mathrm{cm})$. This results in a large dilution of the (more polluted) top layer of the sediment, explaining the relatively low PBDElevels measured in most samples. Covaci et al. analysed two sediment cores from the River Scheldt upstream from Antwerp. ${ }^{25}$ Results showed that PBDE concentrations decreased from $270 \mathrm{ng} \mathrm{g}^{-1} \mathrm{dw}$ in the top layer to $3.7 \mathrm{ng} \mathrm{g}^{-1} \mathrm{dw}$ at $20-25$ $\mathrm{cm}$ depth, without significant profile changes for tri- to hexaBDEs.

To ensure that only the top layer of the sediment is sampled, preferentially a box-corer sampler should be used. In this way dilution is much less pronounced and exposure assessment with regard to biota living above the sediments may be more accurate. Sampling by means of a Van Veen surface sediment sampler can therefore influence the results. Concentrations to which biota are exposed may therefore be higher than reported in this paper. However, PBDE patterns are not altered and can still provide very useful data. ${ }^{25}$

A mean PBDE-profile was calculated for the fish and invertebrates that were previously analysed ${ }^{12}$ and is plotted in Fig. 2. The mean profile of the sediments in the present study was identical to the profile of the Bromkal technical mixture. However, the profile found in fish from the same locations differed statistically significantly from the profiles in the sediments. Metabolic processes are most likely related to this observation, because the bioavailability of tetra- to hexasubstituted congeners is assumed to be equal in marine organisms. $^{26}$

However, benthic invertebrates, that are assumed to have lower metabolic capacity than fish, ${ }^{27}$ display a profile that was not significantly different from the profile of the technical mixture (Fig. 2). The PBDE-profile in the fishes was extensively altered compared to the sediments. This observation suggests that the limited metabolic capacity of the invertebrates does not seem to enable these organisms to change the pattern to the same extent as can be observed in the fishes. BDE 183 and BDE 209 could not be detected in any invertebrate or fish sample, although they were present in the sediments.

Uptake of higher brominated BDEs was very low in controlled feeding experiments. ${ }^{28}$ It was concluded to be related to their high $\log K_{\text {ow }}$ values and their large molecular size, which hinders them in crossing membranes. ${ }^{28}$ Contrarily, in a recent publication by Tomy et al., the uptake of BDE 183 and BDE

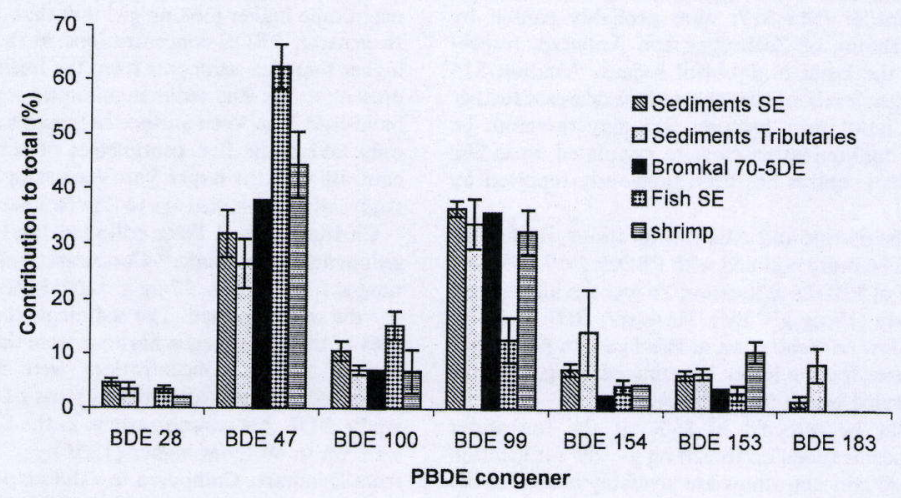

Fig. 2 PBDE profiles in sediments from the SE and freshwater locations, profile of Bromkal 70-5DE and profiles found in biota. ${ }^{12}$ Results for Fish indicate the mean profile for dab, plaice, bib, sole and whiting. The error flags indicate $2 \times$ standard error. 
209 following oral administration was comparable or even higher, respectively, than the uptake of the other congeners. ${ }^{29}$ The absence of BDE 183 and 209 in the biota samples in the study by Voorspoels et al. ${ }^{12}$ and their presence in the sediments suggests that the aquatic uptake of BDE 183 and 209 may therefore be restricted by the physical, rather than by the biological availability.

Relatively fast metabolism of BDE 183 and 209 in fish has been repeatedly reported, ${ }^{28-30}$ which is in agreement with the absence of these congeners in the biota.

To the author's knowledge, no data are available to date concerning metabolism of PBDEs in invertebrates. Possibly a combination of both low uptake and fast metabolism are related to the observation that both BDE 183 and BDE 209 can be found in the sediments, but not in the invertebrates and fish.

\section{Correlations between BDE 209 and other PBDEs}

Only locations at which all measurements were above the LOQ were taken into account for calculating the correlation between BDE 209 and the sum of the other congeners. Levels of BDE 209 and the other PBDEs were significantly positively correlated for all samples from the marine locations (BNS and SE). Log-normalised concentrations showed an $R^{2}$-value of 0.9372 $(p<0.05)$. The input of these 2 groups of contaminants seems to be related for the SE locations.

For the samples taken at the freshwater locations, the correlation between BDE 209 and other PBDE-congeners was not significant. In particular, location T6 displayed rather high levels of all PBDEs except BDE 209. In general BDE 209 was relatively low and the other PBDEs relatively high in the sediments of the tributaries, which points at a different exposure compared to the SE, where the major PBDE-load consists of BDE 209 (up to $98 \%$ ). It can therefore be concluded that the exposure to the lower brominated PBDEs and BDE 209 is different in the SE and in the freshwater watercourses of the Scheldt basin.

\section{Acknowledgements}

We wish to thank VLIZ for their logistic assistance and Dr Andre Cattrijsse and Dr Shaogang Chu for their help with the sampling at the estuarine locations. Dr Lieven Bervoets is kindly acknowledged for providing the freshwater sediments.

\section{References}

1 J. de Boer, K. de Boer and J. P. Boon, The Handbook of Environmental Chemistry, New Types of Persistent Halogenated Compounds, Springer-Verlag, Berlin, Germany, ISBN 3-540$6583-6,2000$, pp. $61-95$
2 Bromine Science and Environmental Forum (BSEF), 2003, Major Brominated flame retardants volume estimates, Brussels, Belgium.

Bromine Science and Environmental Forum (BSEF), 2004. Closure of Deca-BDE Scientific Risk Assessment: European Union decision supports continued use of Deca-BDE, Press release 28 May 2004, Brussels, Belgium.

4 C. A. de Wit, Chemosphere, 2002, 46, 583.

5 J de Boer, T. E. van der Zande, H. Pieters, F. Ariese, C. A. Schipper, T. van Brummelen and D. Vethaak, J. Environ. Monit., $2001,3,386$.

6 M. Ikonomou, S. Rayne, M. Fischer, M. Fernandez and W. Cretney, Chemosphere, 2002, 46, 649.

7 K. Gustafsson, M. Björk, S. Burreau and M. Gilek, Environ. Toxicol. Chem., 1999, 18, 1218

8 I. Watanabe and S. Sakai, Environ. Int., 2003, 29, 665.

9 K. Kuosmanen, T. Hyötyläinen, H. Hartonen and M. J. Riekkola, J. Chromatogr., A, 2002, 943, 113.

10 R. J. Pruell, N. I. Rubinstein, B. K. Taplin, J. A. LiVolsi and R. D. Bowen, Arch. Environ. Contam. Toxicol., 1993, 24, 290.

11 B. J. Reid, K. C. Jones and K. T. Semple, Environ. Pollut., 2000, $108,103$.

12 S. Voorspoels, A. Covaci and P. Schepens, Environ. Sci. Technol., 2003, 37, 4348 .

13 S. Voorspoels, A. Covaci, J. Maervoet, I. De Meester and P. Schepens, Mar. Pollut. Bull., 2004, in press.

14 K. I. Van de Vijver, P. T. Hoff, W. Van Dongen, E. L. Esmans, R. Blust and W. M. De Coen, Environ. Toxicol. Chem., 2003 22, 2037.

15 G. Coteur, P. Gosselin, P. Wantier, Y. Chambost-Manciet, B. Danis, P. Pernet, M. Warnau and P. Dubois, Arch. Environ. Contam. Toxicol., 2003, 45, 190.

16 T. Huybrechts, J. Dewulf and H. Van Langenhove, J. Chromatogr., A, 2003, 1000, 283.

17 C. Allchin, R. Law and S. Morris, Environ. Pollut., 1999, 105, 197.

18 M. Lohman, S. van Leeuwen and J. de Boer, Final report on the feasability of certification of BFRs in sediment - BROC project, RIVO, The Netherlands, 2003.

19 E. J. M. Delhez and G. Carabin, Estuarine Coastal Shelf Sci., $2001,53,477$.

20 J. H. Christensen and J. J. Platz, J. Environ. Monit., 2001, 3, 543.

21 R. J. Law, C R. Allchin, J. de Boer, A. Covaci, D. Hertzke, P. Lepom, S. Morris and C. A. de Wit, BFR 2004 Proc., 2004, 79.

22 J. De Boer, P. G. Wester, A. van der Horst and P. E. G. Leonards, Environ. Pollut., 2003, 122, 63.

23 G. Sawal, B. Stachel and P. Lepom, BFR 2004 Proc., 2004, 151.

24 B. N. Zegers, W. E. Lewis, K. Booij, R. H. Smittenberg, W. Boer, J. de Boer and J. P. Boon, Environ. Sci. Technol., 2003, 37, 3803.

25 A. Covaci, A. Gheorghe, S. Voorspoels, J. Maervoet, E. Steen Redeker, R. Blust and P. Schepens, Environ. Int., 2004, in press.

26 N. G. Dodder, B. Strandberg and R. A. Hites, Environ. Sci. Technol., 2002, 36, 146.

27 K. Borgå, G. W. Gabrielse and J. U. Skaare, Environ. Pollut., $2001,113,187$.

28 A. Kierkegaard, L. Balk, U. Tjärnlund, C. A. de Wit and B. Jansson, Environ. Sci. Technol., 1999, 33, 1612.

29 G. T. Tomy, V. P. Palace, T. Halldorson, E. Braeckevelt, R Danell, K. Wautier, B. Evans, L. Brinkworth and A. T. Fisk, Environ. Sci. Technol., 2004, 38, 1496.

30 H. M. Stapleton, Assimilation and metabolism of Polybrominated diphenyl ethers by the common carp, Cyprinus carpio, Doctoral Dissertation, University of Maryland, United States, 2003. 